\title{
Assessing response capabilities for responding to ship-related oil spills in the Chinese Bohai Sea
}

\author{
Yebao Wang ${ }^{\mathrm{a}, \mathrm{b}, \mathrm{c}, \mathrm{d}}$, Xin Liu ${ }^{\mathrm{a}, \mathrm{c}, \mathrm{d}, \mathrm{e}, *}$, Xiang $\mathrm{Yu}^{\mathrm{f}}$, Xiangyang Zheng ${ }^{\mathrm{a}, \mathrm{c}, \mathrm{d}}$ \\ a Yantai Institute of Coastal Zone Research, Chinese Academy of Sciences, Yantai, Shandong 264003, PR China \\ ${ }^{\mathrm{b}}$ University of Chinese Academy of Sciences, Beijing 100049, PR China \\ ${ }^{\mathrm{c}}$ Key Laboratory of Coastal Environmental Processes and Ecological Remediation, Yantai Institute of Coastal Zone Research, Chinese Academy of Sciences, Yantai, \\ Shandong 264003, PR China \\ d Shandong Provincial Key Laboratory of Coastal Environmental Processes, Yantai Institute of Coastal Zone Research, Chinese Academy of Sciences, Yantai, Shandong \\ 264003, PR China \\ e Crawfold School of Public Policy, Australian National University, ACT 2601, Australia \\ ${ }^{\mathrm{f}}$ School of Resources and Environmental Engineering, Ludong university, Yantai, Shandong 264025, PR China
}

\section{A R T I C L E I N F O}

\section{Keywords:}

Oil spill response capabilities

Ship-related oil spills

Potential spill volume

Expected response capabilities

The Bohai Sea

\begin{abstract}
A B S T R A C T
Various oil spill response facilities and their quantities for twelve major harbors, which are responsible for eight response zones in the Bohai Sea, were investigated using a questionnaire. Four maps were produced to show the actual distribution of response capabilities including the efficiency of oil skimmers, quantity of booms, sorbent materials and vessels. The expected response capabilities for skimmers and booms were calculated and compared with the reality. For skimmers responding to potential spill accidents, there was a large gap between the existing response capability and the expected response capability in most response zones. An increase in the quantity of oil skimmers is therefore recommended to mitigate the harmful effects of future large oil spills caused by potential ship grounding accidents in Response Zones 1, 2, 4 and 5. For booms, Response Zone 1 was found to be the least sufficient, whereas Response Zones 3 and 6 were overprepared.
\end{abstract}

\section{Introduction}

Oil spills in the marine environment are frequently seen all over the world. For example, 592 tanker spills of over $7 \mathrm{t}$ have occurred all over the world from 1990 to 2017, In 2017 alone, four medium-sized spills $(7-700 t)$ and two large-sized ( $>700 t$ ) spill were recorded according to the International Tanker Owners Pollution Federation [1]. In the past 30 years, representative ship-related oil spill accidents; for example, the Exxon Valdez in America (1989) and the Prestige in Spain (2002) both had negative impacts on surrounding regions. They caused substantial environmental, ecological, and economic damage to the neighboring regions to the spill site $[2,3]$, and even sociocultural and psychosocial impacts [4]. Researchers have examined many aspects for oil spills, including monitoring the distribution of oil slicks using remote sensing images $[5,6]$, simulating the trajectories of spilled oil with mathematical models [7], and estimating environmental and economic costs resulting from oil pollution [8-11]. When dealing with the accidents, cleaning up the oil at the beginning of the accidents is critical, as a rapid response could minimize the influence of pollution on surrounding areas. In order to respond effectively at the very start of these spillages, a range of marine oil spill cleanup methods and techniques have been developed, such as mechanical methods, chemical methods, bioremediation, and in situ burning [12].

However, each method has its limitations. The use of chemical dispersion in a real spill contingency response at sea is typically not supported because of the toxicity of the early dispersant formulations on aquatic organisms [13-15]. Bioremediation is used only on land, and generally used as a supplemental cleanup technology [16] and is limited by several factors, such as dissolved oxygen concentration, nutrient availability, temperature, and salinity [17]. The window of opportunity for in situ burning is limited and fires could threaten human life, property and resources [18]. Mechanical methods can be effective, depending on the type of oil and environmental conditions. They could be considered the most environmentally friendly option, as they involve the direct removal of the pollution from the sea. Therefore, mechanical methods are taken as the most common oil spill countermeasure despite the high capital investment and complex operation.

The Chinese Bohai Sea is a typical semi-enclosed shallow sea with an average depth of $18 \mathrm{~m}$ and maximum depth of $70 \mathrm{~m}$ with a rich biodiversity and abundance of marine life. The Bohai Sea is covered

\footnotetext{
* Corresponding author at: Yantai Institute of Coastal Zone Research, Chinese Academy of Sciences, Yantai, Shandong 264003, PR China.

E-mail address: xliu@yic.ac.cn (X. Liu).
} 
densely by ship routes and the transport of crude oil by ships and tankers has become increasingly frequent. Should accidents occur in this area, in situ burning is not suggested because of it will produce a lot of toxic smoke which is harmful to human health. The smoke would likely fall out over the populated urban areas around the Bohai Sea, depending on distance to shore from the fire and prevailing winds. Moreover, many countries have set certain restrictions on spraying based on the water depth and/or the distance from shore [19]; therefore, dispersants also cannot be used in the Bohai Sea. Thus, mechanical methods are the primary response option for combating oil spills in the Bohai Sea. However, the actual oil spill response capability in the Bohai Sea has not been fully studied because of a lack of data, although improvements to the response capability all over China has been previously recommended [20].

In this study, we obtained the storage quantity of many mechanical recovery facilities for oil spills based on a questionnaire in a survey. The potential maximal spill size following ship accidents was estimated for each sea area. The expected response capability was estimated based on the estimated spill size and compared with the actual oil spill response capability. This research presents an assessment of the actual oil spill response capability in the Bohai Sea, and provides an expected response capability for future response to large-scale oil spills caused by ship accidents.

\section{Data and methods}

The study area covers the entire Bohai Sea area $\left(117.5-122.5^{\circ} \mathrm{E}\right.$ longitude and $37-41^{\circ} \mathrm{N}$ latitude). There are three major bays and one strait in the Bohai Sea: Laizhou Bay, Liaodong Bay, Bohai Bay, and the Bohai Strait (Fig. 1). Oil spill accidents could cause great damage to the coastal environment because of the shallow water and enclosed C-shape of the Bohai Sea. It is therefore necessary to prepare sufficient emergency facilities to deal with potential spills in the future.

There are two maritime-related authorities in China: the State Oceanic Administration (SOA) and the Maritime Safety Administration (MSA). The SOA is responsible for combating spills related to nearshore and offshore oil drilling activities, whereas the MSA is in charge of harbor response to ship-related oil spill accidents. Oil spill response facility depots are in the charge of MSA in China. In order to response spill accidents as quickly as possible, the Bohai Sea was split into eight response zones by the MSA. It is noteworthy that three response zones share the surface of the Bohai Bay (Zones 2, 3 and 4), with the reason that the Bohai Bay is the busiest area in the Bohai Sea. Information on the maximum tonnage of oil tanker that the harbors can hold in each response zone were provided by the MSA and are indicated in Fig. 1. Some zones such as Zone 1 contain more than one harbor and thus we selected the largest tonnage of oil tanker that these harbors could hold to represent the maximum tonnage of oil tanker in the zone.

\subsection{Questionnaire survey}

To obtain data on the storage quantity of mechanical response facilities, to further analyze the actual mechanical response capability, and to finalize assessment of the expected response capability in the Bohai Sea, we designed a questionnaire specific to this study (presented in the Appendix). The questionnaire contained two parts: a short introduction and the questions on the storage quantity of the mechanical oil recovery facilities. The respondents were the departments for hazardous materials administration of MSA, and thus the questionnaire did not require a signature from the personnel who fill in the form, but the name of harbors and dates were necessary for the convenience of post-processing. The authoritative respondents ascertained the accuracy to the greatest extent possible. We delivered the questionnaires to all local MSA units, which administrated 21 harbors along the Bohai Sea. A total of 21 questionnaires were released and all of them were responded. The perfect rate of recovery probably results from the official character of the investigation; the questionnaires were released with a request for cooperation, alongside an official letter of our institute. According to feedback from the respondents, nine small harbors do not hold any response facilities although they also can be affected by an oil spill. Analysis of the relevant statistics indicated that these small harbors are generally fishing ports that cannot berth large ships, but they consistently share the same response zones with large harbors. Once the oil spill accidents occur in a specific zone, large harbors with facility stockpiles will sustain the response action for the whole zone (the fishing ports will receive support from the nearby harbors that maintain response facilities). Therefore, 12 valid questionnaires were obtained after screening out the 9 invalid questionnaires, which did not influence the subsequent evaluation of the emergency capabilities for a potential spill. The 12 harbors that maintain response facilities are: Weihai, Yantai, Weifang, Dongying, Binzhou, Huanghua, Tianjin, Tangshan, Qinhuangdao, Jinzhou, Dalian, and Zhuanghe (Fig. 1).

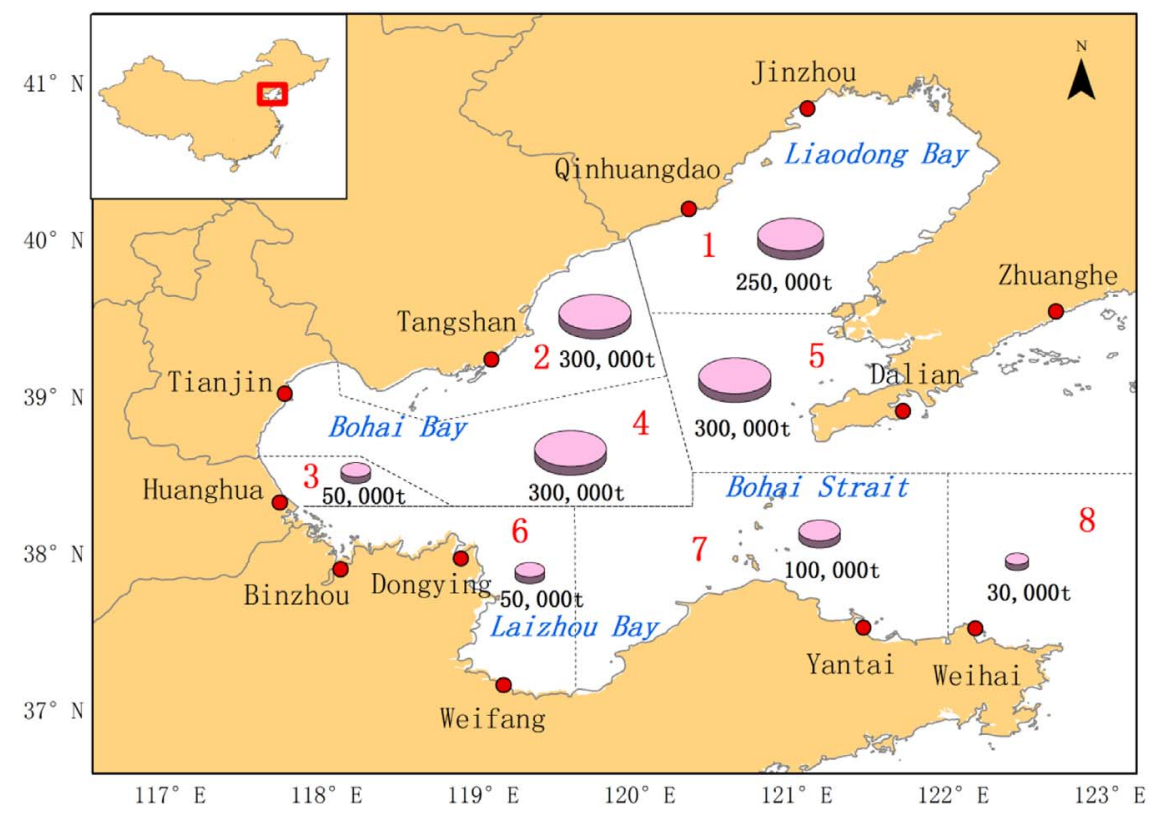

Fig. 1. The Chinese Bohai Sea (three bays and one strait) split into eight response zones by the MSA (Maritime Safety Administration). The red points represent the location of 12 key harbors along the Bohai Sea. The eight response zones are indicated by black dotted lines and a red number from 1 to 8 . The maximal tonnage of an individual oil tanker that each zone can hold is indicated by a bold number and pink circle. (For interpretation of the references to color in this figure legend, the reader is referred to the web version of this article.) 


\subsection{Calculation of the potential size of a spill}

The semi-enclosed Bohai Sea is considered to be one of the most intensive areas of maritime traffic in China [21]. The number of large ships transporting crude oil has increased with the rapid economic development of the area but this has a corresponding higher risk of large-scale oil spill accidents. It is important to assess the potential maximal spill size that could be caused by oil tankers in the region. Major ship oil spills are usually caused by misoperation such as grounding and collisions that typically occur outside harbors in offshore areas. Grounding is by far the most frequent form of accident [22] and the bottom which is made up of rocks usually is seen as the main cause of accidents $[23,24]$, so this study largely focused on grounding accidents. Possible future spill size can be estimated based on the ship size and accident type [25]. Using data from the International Petroleum Industry Environmental Conservation Association [26], a regression analysis was applied to represent the relationship between the potential oil spill size and deadweight of ships in grounding accidents. The regression equation is as follows:

$P S Z=\left(2 \times 10^{-7}\right) \times D W T^{2}+0.2169 \times D W T-4275.9$

where PSZ is the potential spill size and DWT is the deadweight tonnage of an individual oil tanker.

\subsection{The expected oil spill recovery efficiency of skimmer}

The expected efficiency of recovery for skimmers (AR) can be estimated using the equation given by the Korean National Marine Oil Spill Contingency Plan [27]:

$A R=R D /(D W \times M E \times P E \times M R)$,

where $R D$ is the expected daily removal amount, $D W$ is the daily number of working hours (the default value is $8 \mathrm{~h}$ ), $M E$ is the mechanical efficiency (the default value is 0.2 ), $P E$ is the performance efficiency (the default is 0.65 ), and $M R$ is the mobilization rate (the default is 0.33). This equation was validated in previous study [28].

\subsection{Algorithm for expected capabilities of floating booms}

According to the Ministry of Transport of the People's Republic of China (MOT), the total capabilities of floating booms for oil response can be assessed with the following equation [29]:

$L=L_{1}+L_{2}+L_{3}+L_{4}$,

where $L$ is the total length of various floating booms, $L_{1}$ is the length of the booms from ships to surrounding and controlling the oil on-site; $L_{2}$ is the length of the booms for working with the skimmers, $L_{3}$ is the length of the booms for preventing oil from dispersing and drifting with driving force of winds and currents, and $L_{4}$ is the length of the booms for protecting the coasts and sensitive resources.

The MOT also provided information on estimating $\mathrm{L}_{1}, \mathrm{~L}_{2}, \mathrm{~L}_{3}$ and $\mathrm{L}_{4}$. These equations are as follows:

$L_{1} \geq 3 *(B+W)^{*} N_{1}$,

where $B$ is the length of the tanker, $W$ is the width of the tanker, and $N_{1}$ is the number of layers which will be deployed. In our study, $N_{1}$ was assumed to be 2 .

$L_{2}=D^{*} 100$,

where $D$ is the expected number of skimmers and can be estimated as follows:

$D=A R / E S$,

where $A R$ is the expected efficiency of the recovery skimmer, and $E S$ is the efficiency of an individual skimmer. According to our questionnaire survey, the average efficiency of an individual skimmer is about
$100 \mathrm{~kL} / \mathrm{h}$ (abbreviation for kiloliter/hour) stored in the harbors, so ES was defined as $100 \mathrm{~kL} / \mathrm{h}$ in this study.

$L_{3}=U^{*} N_{2}$,

where $U$ is the length of one set of booms, and $N_{2}$ is the total number of sets of booms. As $\mathrm{L}_{3}$ depends on factors such as the area of spilled oil, wind velocity, and current velocity, it is complicated to determine $N_{2}$. We conservatively assumed $N_{2}$ is 10 , representing 10 sets of booms and $U$ is $400 \mathrm{~m}$ for each set of booms.

$L_{4}=\left(L_{1}+L_{2}+L_{3}\right)^{*} \phi$,

where $\varphi$ is a weighting coefficient between 0.2 and 0.5 . The higher the environmental sensitivity, the larger the weighting coefficient. In this study, we set $\varphi$ as 0.2 for a conservative estimation.

\section{Results}

\subsection{Existing response capabilities responding to ship-related oil spills}

Response facilities are used to prevent or reduce the adverse socioeconomic and environmental impact of spilled oil on the affected area. In our study, the response capabilities can be represented by the preparedness and effectiveness of recovery facilities. Transporting the cleanup facilities from remote harbors to the spill site is time consuming and the response activities are also often urgent. Therefore, it is necessary for local harbors to retain enough facilities to respond to oil spills. Based on the questionnaires from local MSA, the storage quantity of the four main mechanical cleanup facilities (oil skimmers, oil spill booms, sorbent materials, and tug and response vessel) were obtained (Fig. 2).

Statistics from the survey indicated that the total storages of these facilities in the selected local MSA along the Bohai Sea were $133,420 \mathrm{~m}$ for floating booms, $9632 \mathrm{~kL} / \mathrm{h}$ for skimmers, $228.94 \mathrm{t}$ for sorbent materials and 100 vessels. To indicate the distribution of these facilities, the quantity of these facilities in the eight administrative response zones are represented by histograms in Fig. 2 .

Regarding all four facilities, it is clear that the most intensive location is the Bohai Bay area. This is consistent with previous work [30] that indicated that Bohai Bay is also the most intensive area of ships for the year of 2007, 2009 and 2010. The distribution of response facilities is consistent with the provisional distribution of ships in the Bohai Sea. In contrast, Liaodong Bay is relatively less well prepared.

\subsection{The potential oil spill size}

In order to efficiently control spilled oil, adequate facilities must be prepared and should be deployed immediately after the spill. However, every accident has individual characteristics (such as spill site, spill size, weather conditions, and oil type), which leads to a different quantity of facilities required. We assumed in this study that the spilled oil was heavy crude oil with a density of $879.5 \mathrm{~kg} / \mathrm{m}^{3}$ and the spill size was linked with the maximal deadweight of the oil tankers (Section 2.2).

Based on the algorithm presented in Sections 2.3 and 2.4, we proposed an expected efficiency for skimmers and an expected quantity for booms, respectively. The worst scenario was estimated in those different response zones, namely the specific tanker with a maximal deadweight was fully loaded with heavy crude oil and grounded in particular areas. Therefore, the potential spill size could be estimated by Eq. (1). In accordance with the Natural Research Council Report of America 2003 [31], one-third of the spilled oil is expected to be cleaned up in water by the response facilities within 3 days following the spill and the remainder is expected to be removed by weathering processes and the help of recovery onshore [28]. For example, the maximal deadweight tonnage of an individual tanker in Zone 5 is 300,000, and thus the worst possible oil spill size was estimated to be $78,794 \mathrm{t}$ 

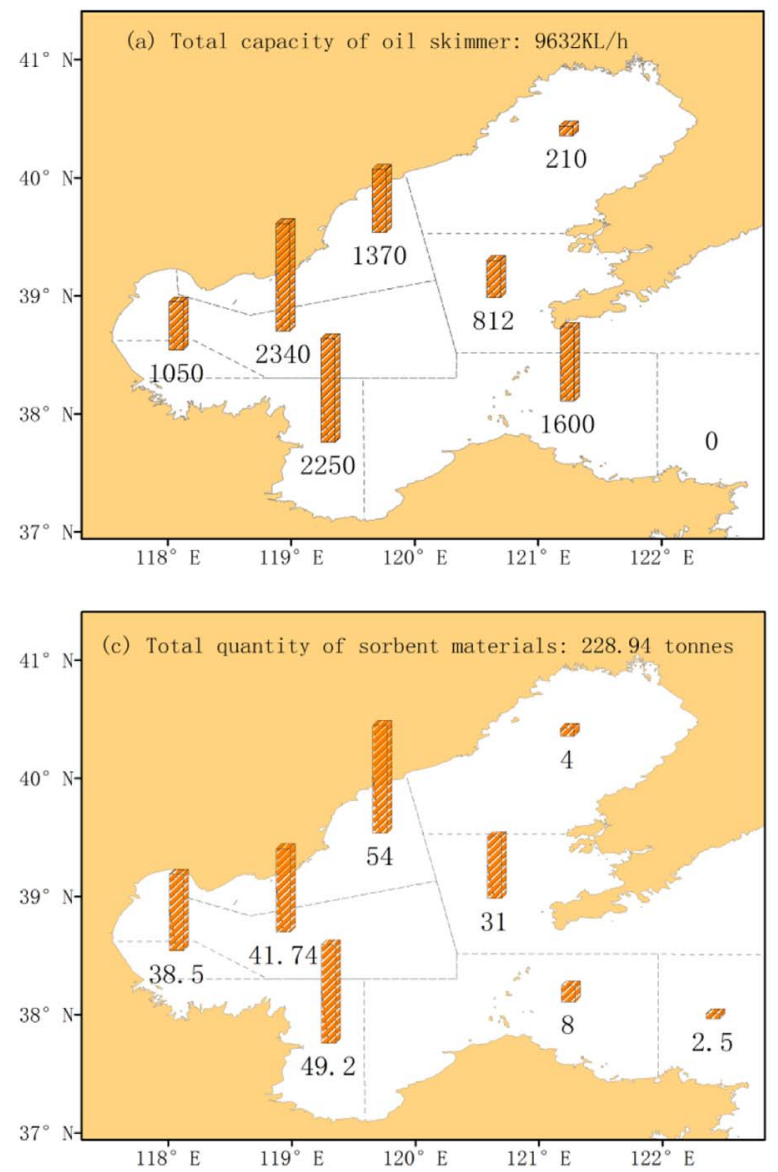
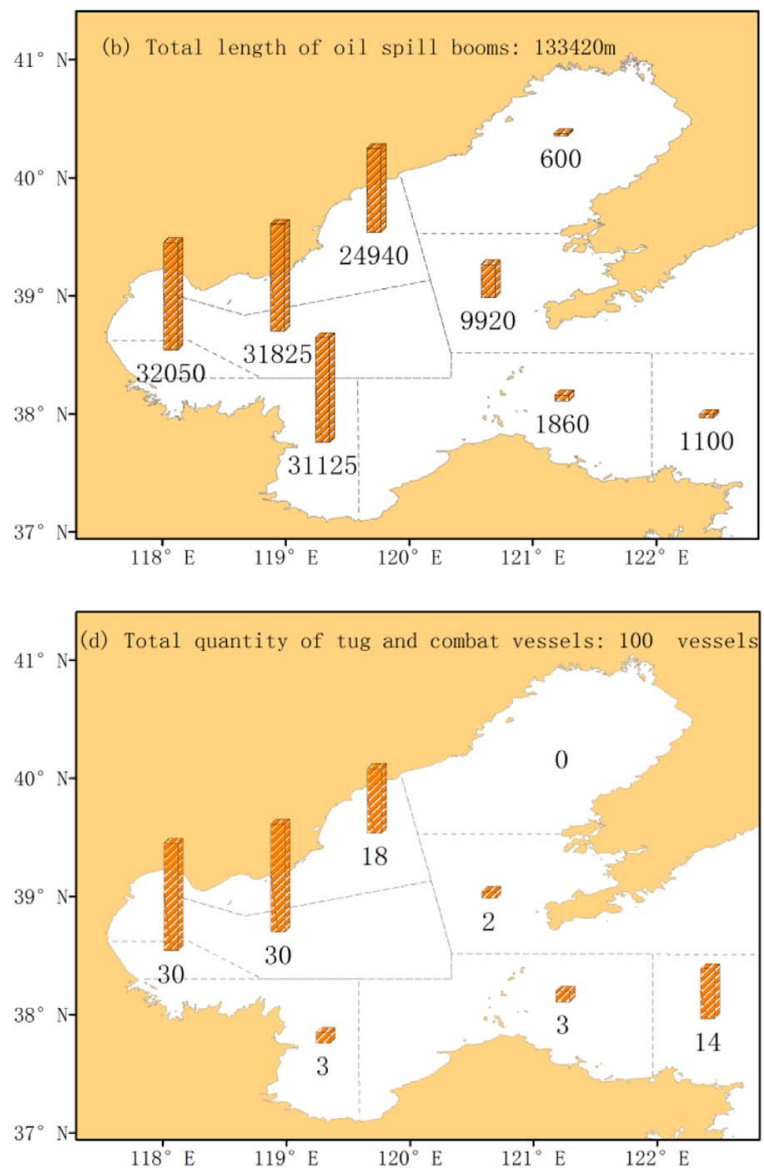

Fig. 2. (a) Capacity of oil skimmers, (b) length of oil spill booms, (c) quantity of sorbent materials, (d) quantity of tug and response vessels.

Table 1

The potential spill size and $R D$ for the eight response zones.

\begin{tabular}{|c|c|c|c|c|c|}
\hline $\begin{array}{l}\text { Response zone } \\
\text { number }\end{array}$ & Harbors & $\begin{array}{l}\text { Maximum deadweight of an individual } \\
\text { tanker the zone can hold (tons) }\end{array}$ & $\begin{array}{l}\text { Maximal potential } \\
\text { spill size (tons) }\end{array}$ & $\begin{array}{l}\text { Estimated oil to be mechanically } \\
\text { removed (tons) }\end{array}$ & $\begin{array}{l}\text { Estimated daily removal } \\
\text { amount (tons) }\end{array}$ \\
\hline 1 & Jinzhou, Qinhuangdao & 250,000 & 62,449 & 20,816 & 6939 \\
\hline 2 & Tangshan & 300,000 & 78,794 & 26,265 & 8755 \\
\hline 3 & Huanghua & 50,000 & 7069 & 2356 & 785 \\
\hline 4 & Tianjin & 300,000 & 78,794 & 26,265 & 8755 \\
\hline 5 & Dalian, Zhuanghe & 300,000 & 78,794 & 26,265 & 8755 \\
\hline 6 & $\begin{array}{l}\text { Binzhou, Dongying, } \\
\text { Weifang }\end{array}$ & 50,000 & 7069 & 2356 & 785 \\
\hline 7 & Yantai & 100,000 & 19,414 & 6471 & 2157 \\
\hline 8 & Weihai & 30,000 & 2411 & 804 & 268 \\
\hline
\end{tabular}

according to formula (1). Therefore, $26,265 \mathrm{t}$ as one-third of the potential spill size was expected to be removed by mechanical recovery facilities and the expected $R D$ for such a potential spill was $8755 \mathrm{t}$. The estimated results for all response zones are presented in Table 1.

\subsection{Evaluating skimmer recovery capability}

Comparison of the expected efficiency of skimmers with the actual efficiency of skimmers in each of the eight response zones, there was an order of magnitude difference in Zones 1, 2, 4 and 5 (Fig. 3).

Taking Zone 5 as an example, its expected efficiency of skimmers is $25,510 \mathrm{~kL} / \mathrm{h}$; however, the total actual efficiency of skimmers in the whole Bohai Sea area is $9632 \mathrm{~kL} / \mathrm{h}$ only. It is clear that such a requirement still cannot be met, even if all the skimmers distributed along the Bohai Sea were gathered. In contrast, the gap is much smaller in Zones $3,6,7,8$. These zones have adequate skimmers relative to their expectations. If the potential maximal spill were to occur in Zone 6, stored skimmers could be expected to be capable to handle the in-situ recovery of spilled oil. In contrast, more skimmers would need to be transported from neighboring areas to help recover oil from spills in Zones 3,7 , or 8 , as their actual skimmers' recovery abilities are insufficient. In general, this comparison indicates that the actual efficiency of skimmers stored along the Bohai Sea is too far behind the expectations that have been calculated to deal with the worst-case future oil spill scenario, if stockpiles of other sea areas in China and neighboring countries are not considered.

\subsection{Evaluation of boom length}

The expected length of oil booms was evaluated by Eqs. (3)-(8). All parameters calculated are shown in Table 2 and the expected length of booms $(L)$ was estimated for all eight response zones. We compared the expected quantity of booms with the actual quantity of booms (Fig. 4) and found that the gap was relatively small in Zones 2 and 4. In these 


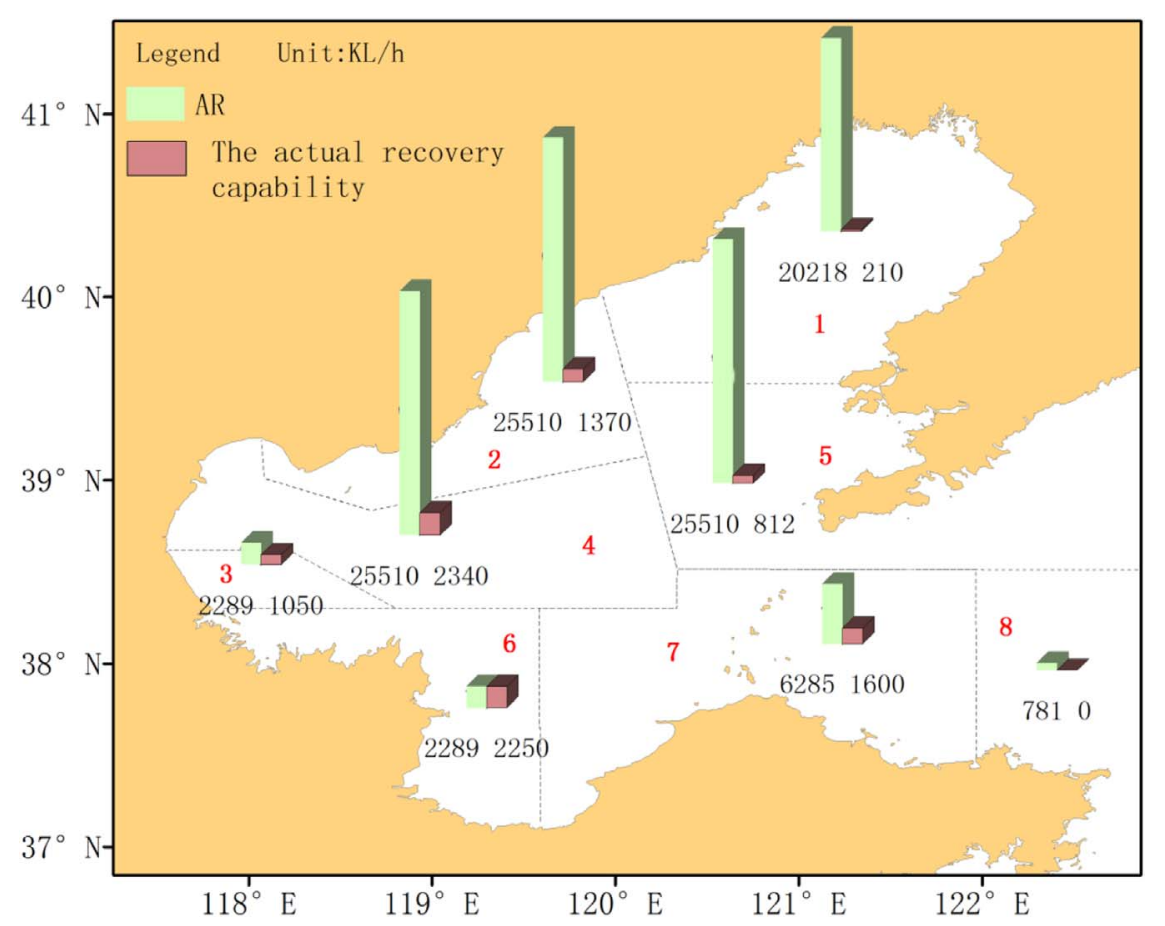

Fig. 3. Comparisons between the expected efficiency of recovery for skimmers (AR) and the actual efficiency of skimmers.

zones, the booms stored could mostly meet the oil contingency plan to respond to an emergency. However, there were severely insufficient booms in Zones 1, 5, 7, and 8, and thus more booms need to be equipped to deal with a worst-case oil spill in the future. However, it was noted that the booms were over-equipped in Zones 3 and 6, whose expected quantity of booms was much less than its actual quantity. We therefore suggest that booms are moved from Zones 3 and 6 to other zones in which the boom storage is insufficient.

\section{Discussions}

Estimating oil spill response activities is complex because oil removal can be influenced by numerous factors such as the comprehensive use of different facilities, rescuer quality, the influence of bad weather, and sea conditions. In this study, the influence from human and exterior environment factors were ignored to eliminate interference and simplify the evaluation. Furthermore, in view of the physical truth of the Bohai Sea, this study focused only on the mechanical emergency capabilities for the removal of spilled oil. According to Ventikos et al. [12], barriers/booms, skimmers, skimmer vessels and sorbent materials are the actual methods used in the mechanical cleanup approach, and the response capability could be estimated based on these. Basically, a mechanical system should consist of a skimmer, a boom, a boat, some personnels and a storage tanker [36]. Furthermore, emergency logistics is also important [37]. This study mainly focus on the abilities of booms and shimmers other than personnels, storage tankers and logistics. In general, only skimmers are used most of the time for the evaluation of recovery effectiveness, because they represent an integral part of the overall oil spill response [38]. For examples, the preparedness of skimmers was applied by Lee and Jung [28] to evaluate the capability of response measures to spill accidents in South Korea. The facilities mentioned by Ventikos et al. [12] are representative of modern practice. In our research, four types of response resources including oil skimmers, booms, sorbent materials, and vessels were surveyed using a questionnaire approach. This represents a comprehensive analysis of the actual emergency response capabilities in the Bohai Sea. In contrast, the seldom-used facilities were ignored, since they are less representative and difficult to survey, although they might play some role in the emergency action. Spilled oils on the sea are typically recovered using skimmers and contained using booms [39] and thus the gap between the actual storages and the expected quantity were evaluated for skimmers, and especially for booms.

The formulas used for the evaluation of required quantity of booms were taken from the 'Guidelines on the assessment of ship-source oil spill response capability' issued by MOT, and they were inferred based on a number of different experiences. Although it is difficult to verify the calculations since the worst scenario has not yet occurred, the formulas remain based on best practice. Of course, some deviation is unavoidable

Table 2

Calculation parameters for expected quantity of booms.

\begin{tabular}{|c|c|c|c|c|c|c|c|c|c|c|}
\hline Zone number & Maximum deadweight of tanker that the block can hold & $B(\mathrm{~m})$ & $W(\mathrm{~m})$ & $A R(\mathrm{kl} / \mathrm{h})$ & $D$ & $L_{1}(\mathrm{~m})$ & $L_{2}(\mathrm{~m})$ & $L_{3}(\mathrm{~m})$ & $L_{4}(\mathrm{~m})$ & $L(\mathrm{~m})$ \\
\hline 1 & 250,000 & 315 & 56 & 20,218 & 202 & 2226 & 20,200 & 4000 & 5285 & 31,711 \\
\hline 2 & 300,000 & 333 & 58 & 25,510 & 255 & 2346 & 25,500 & 4000 & 6369 & 38,215 \\
\hline 3 & 50,000 & 183 & 32 & 2289 & 23 & 1290 & 2300 & 4000 & 1518 & 9108 \\
\hline 4 & 300,000 & 333 & 58 & 25,510 & 255 & 2346 & 25,500 & 4000 & 6369 & 38,215 \\
\hline 5 & 300,000 & 333 & 58 & 25,510 & 255 & 2346 & 25,500 & 4000 & 6369 & 38,215 \\
\hline 6 & 50,000 & 183 & 32 & 2289 & 23 & 1290 & 2300 & 4000 & 1518 & 9108 \\
\hline 7 & 100,000 & 246 & 42 & 6285 & 63 & 1728 & 6300 & 4000 & 2406 & 14,434 \\
\hline 8 & 30,000 & 173 & 30 & 781 & 8 & 1218 & 800 & 4000 & 1204 & 7222 \\
\hline
\end{tabular}

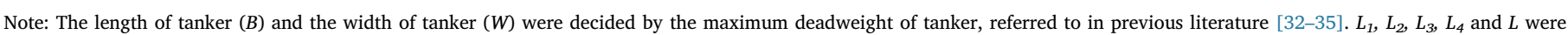
calculated according to Eqs. (3)-(8). 


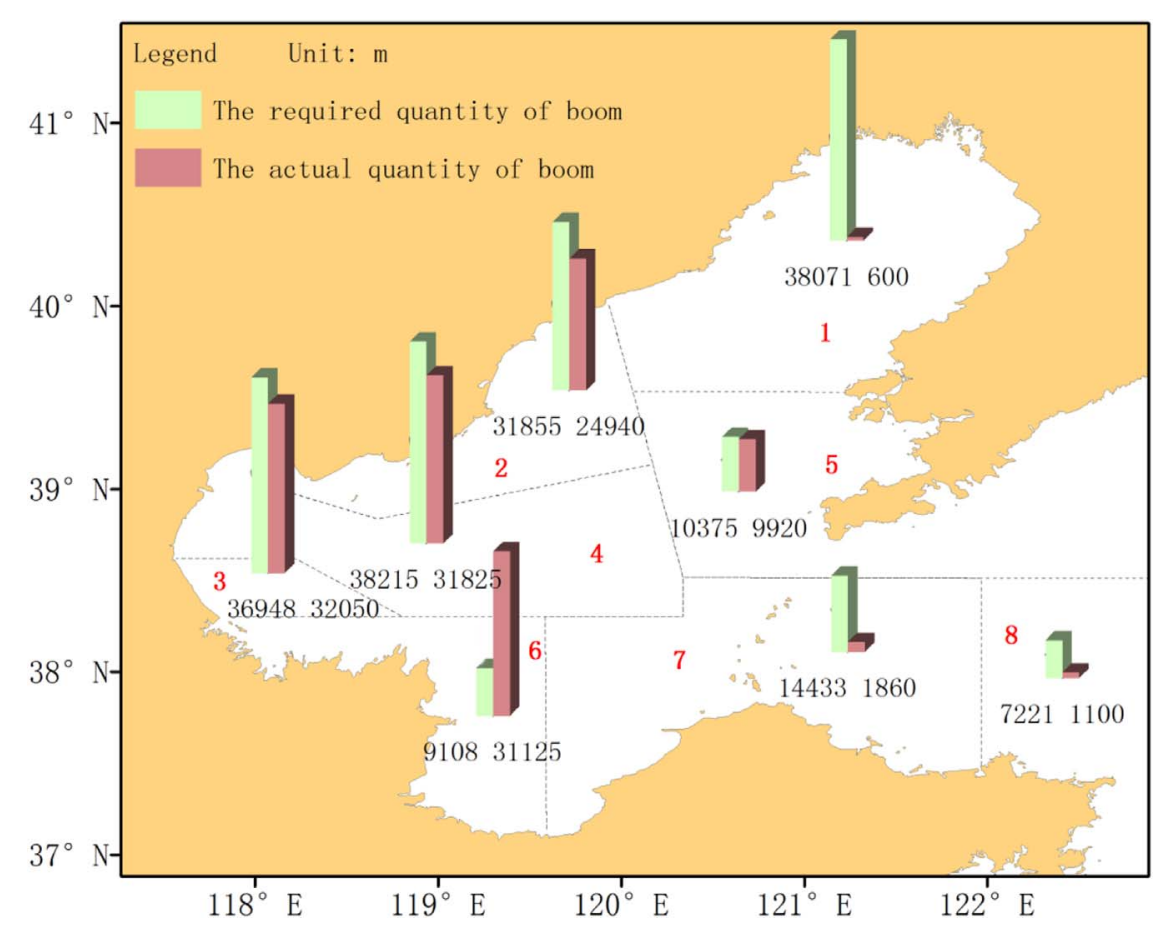

Fig. 4. Comparisons between the actual quantity of booms and the expected quantity of booms.

because of the empirical formulas, and it is difficult to calculate the required quantity very precisely; however, the accuracy could be guaranteed In view of the authoritative source of the formulas.

The survey of the efficiency of skimmers and quantity of booms presented in this study is valuable because we can access to the actual oil spill response capabilities and compare it with the expected response capabilities. For skimmers, it is clear that the actual response efficiency is much lower than the expected efficiency of skimmers for the worst potential spill accident in the Bohai Sea. Thus, there would be insufficient skimmers to respond to spillages should the worst scenario occur in the future. The expected efficiency of skimmers $(A R)$ should be maintained to prepare for a worst spill accident and respond in a timely fashion. All zones but Zone 3 and 6 had insufficient booms to deal with the worst oil leakage from the tanker.

Compared with skimmers and booms, it would be difficult to estimate the expected quantity of sorbent materials and vessels because of the lack of exact calculation methods. Oil sorbent materials can be categorized into natural organic sorbent materials, mineral or natural inorganic sorbent materials, and synthetic sorbent materials [12]. These sorbent materials have different characteristics such as oil absorption, absorption capacity and absorption selectivity. Natural sorbents are different from the commercial synthetic sorbents because they are bio-degradable, eco-friendly, and readily available [40]. Therefore, these materials should be used in response to the specific circumstances of spill accidents. As a result of the specificity of the sorbent method to characteristics of a spill, it is difficult to make a precise calculation method for sorbent materials. Moreover, difficulties also exist in estimating the expected abilities of vessels, especially response vessels. Different types of vessels have different response speed and operational efficiency. The large oil spill recovery vessels take more time to deploy and are operationally more complicated, although they have much larger storage tanks for recovered oil. In contrast, the relatively small oil spill recovery vessels can be rapidly transported to the oil spill area but inefficient. Therefore, the expected recovery abilities of vessels are affected by the spill site rather than the spill volume. The larger vessels are suitable for open seas and the smaller vessels are suitable for inshore areas or marginal seas. Moreover, at some harbors, some commercial vessels can be rapidly converted to oil spill response vessels for oil pollution response activities, but these were not considered as recovery vessels in this study. All these factors indicate that it is difficult to obtain the expected quantity of vessels and compare this value with the actual quantity of vessels.

\section{Conclusions}

In this study, we attempted to assess the volume of oil from a potential oil spill and estimate the recovery responses to ship-related oil spills in the Chinese Bohai Sea. Data were taken from a survey in which questionnaires were sent to local MSAs within the Bohai Sea.

In general, the actual storage quantity should be kept at the level of the expected quantity because of the complexity of an oil spill accident. This research reveals that although some response facility stockpiles have been established by governments, these response resources remain insufficient to deal with potential future large-scale oil spill pollution accidents occurring in this area of the sea.

Although the authorities should prioritize the management of marine oil spill pollution, some local governments in the coastal regions of China still hold the point of view that developing the economy is the most important affair. Therefore, it is easy to understand why preparedness and response capabilities for oil spills are currently not sufficient. Today, the governments should play a more important role in the response mechanism responding to ship related oil spills, and societal forces should take a more active part in the establishment of such a mechanism. The focus should be on the sensitive zones for oil spills, especially in high-risk areas such as Bohai Bay.

\section{Acknowledgments}

The authors would like to thank the Zhuanghe Maritime Safety Administration, Dalian Maritime Safety Administration, Jinzhou Maritime Safety Administration, Qinhuangdao Maritime Safety Administration, Tangshan Maritime Safety Administration, Tianjin Maritime Safety Administration, Huanghua Maritime Safety Administration, Binzhou Maritime Safety Administration, Dongying Maritime Safety Administration, Weifang Maritime Safety Administration, Yantai Maritime Safety Administration and Weihai 
Maritime Safety Administration who provided the data of response facilities.

\section{Funding}

This work was supported by the NSFC41371483 grant from the National Natural Science Fund of China.

\section{Appendix A. Supporting information}

Supplementary data associated with this article can be found in the online version at http://dx.doi.org/10.1016/j.ijdrr.2018.02.040.

\section{References}

[1] ITOPF, International Tanker Owners Pollution Federation Limited. London, United Kingdom. Available on line on < 〈http://www.itopf.com/fileadmin/data/Photos/ Statistics/Oil_Spill_Stats_2017_web.pdf $\rangle>$.

[2] O.R. Harrison, An overview of the Exxon Valdez oil spill, in: International Oil Spill Conference, 1991, pp. 313-319.

[3] B. Laffon, T. Rábade, E. Pásaro, J. Méndez, Monitoring of the impact of Prestige oil spill on Mytilus galloprovincialis from Galician coast, Environ. Int. 32 (3) (2006) 342-348.

[4] D.A. Gill, L.A. Ritchie, J.S. Picou, Sociocultural and psychosocial impacts of the exxon valdez oil spill: twenty-four years of research in Cordova, Alaska, Extr. Ind. Soc. 3 (4) (2016) 1105-1116.

[5] C. Brekke, A.H.S. Solberg, Oil spill detection by satellite remote sensing, Rem. Sens. Environ. 95 (1) (2005) 1-13.

[6] M. Fingas, C. Brown, Review of oil spill remote sensing, Mar. Pollut. Bull. 83 (1) (2014) 9-23.

[7] M. Reed, Ø. Johansen, P.J. Brandvik, P. Daling, A. Lewis, R. Fiocco, D. Mackay, R. Prentki, Oil spill modeling towards the close of the 20th century: overview of the state of the art, Spill Sci. Technol. Bull. 5 (1) (1999) 3-16.

[8] D.S. Etkin, A worldwide review of marine oil spill fines and penalties, Environ. Res. Consult. (2003) 1-158.

[9] D.S. Etkin. Worldwide analysis of marine oil spill cleanup cost factors. Presented at the Arctic and Marine Oilspill Program Technical Seminar, 2000, pp. 1-14.

[10] J. Montewka, M. Weckström, P. Kujala, A probabilistic model estimating oil spill clean-up costs-A case study for the Gulf of Finland, Mar. Pollut. Bull. 76 (1-2) (2013) 61-71, http://dx.doi.org/10.1016/j.marpolbul.2013.09.031.

[11] Y. Yamada, The cost of oil spills from tankers in relation to weight of spilled oil, Mar. Technol. 46 (4) (2009) 219-228.

[12] N.P. Ventikos, E. Vergetis, H.N. Psaraftis, G. Triantafyllou, A high-level synthesis of oil spill response equipment and countermeasures, J. Hazard. Mater. 107 (1-2) (2004) 51-58.

[13] E. Cotou, I. Castritsi-Catharios, M. Moraitou-Apostolopoulou, Surfactant-based oi dispersant toxicity to developing nauplii of Artemia: effects on ATPase enzymatic system, Chemosphere 42 (8) (2001) 959-964.

[14] A.T. Law, Toxicity study of the oil dispersant Corexit 9527 on Macrobrachium rosenbergii (de Man) egg hatchability by using a flow-through bioassay technique, Environ. Pollut. 88 (3) (1995) 341-343.

[15] S.D. Ramachandran, P.V. Hodson, C.W. Khan, K. Lee, Oil dispersant increases PAH uptake by fish exposed to crude oil, Ecotoxicol. Environ. Saf. 59 (3) (2004) 300-308.
[16] P.H. Pritchard, J.G. Mueller, J.C. Rogers, F.V. Kremer, J.A. Glaser, Oil spill bioremediation: experiences, lessons and results from the Exxon Valdez oil spill in Alaska, Biodegradation 3 (1992) 315-335.

[17] A.P. Rosa, J.A. Triguis, Bioremediation process on Brazil shoreline, Environ. Sci. Pollut. Res. 14 (7) (2007) 470-476.

[18] J.V. Mullin, M.A. Champ, Introduction/overview to in situ burning of oil spills, Spill Sci. Technol. Bull. 8 (4) (2003) 323-330.

[19] H. Chapman, K. Purnell, R.J. Law, M.F. Kirby, The use of chemical dispersants to combat oil spills at sea: a review of practice and research needs in Europe, Mar. Pollut. Bull. 54 (7) (2007) 827-838.

[20] S. Xiong, H. Long, G. Tang, J. Wang, H. Li, The management in response to marine oil spill from ships in China: a systematic review, Mar. Pollut. Bull. 96 (1-2) (2015) $7-17$.

[21] J.X. Liu, X.B. Han, Survey and analysis of vessel traffic flow in the Bohai Strait, Ship Ocean Eng. 37 (4) (2008) 95-98 (In Chinese).

[22] M.S. Samuelides, N.P. Ventikos, I.C. Gemelos, Survey on grounding incidents: statistical analysis and risk assessment, Ships Offshore Struct. 4 (1) (2009) 55-68.

[23] B.C. Simonsen, Ship grounding on rock-I. Theory, Mar. Struct. 10 (7) (1997) 519-562.

[24] L. Zhu, P. James, S. Zhang, Statistics and damage assessment of ship grounding, Mar. Struct. 15 (4-5) (2002) 515-530.

[25] P.T. Pedersen, S. Zhang, Effect of ship structure and size on grounding and collision damage distributions, Ocean Eng. 27 (11) (2000) 1161-1179.

[26] International Petroleum Industry Environmental Conservation Association (IPIECA), A Guide to Contingency Planning for Oil Spills on Water. IPIECA Report Series, 2, 2000, pp. 1-28.

[27] Korea Coast Guard(KCG) Korean National Marine Oil Spill Contingency Plan. (in Korean), 1999.

[28] M. Lee, J.Y. Jung, Risk assessment and national measure plan for oil and HNS spill accidents near Korea, Mar. Pollut. Bull. 73 (1) (2013) 339-344.

[29] Ministry of Transport of the People's Republic of China (MOT) Guidelines on the assessment of ship-source oil spill response capability. (In Chinese), 2013.

[30] X. Liu, R. Meng, Q. Xing, M. Lou, H. Chao, L. Bing, Assessing oil spill risk in the Chinese Bohai Sea: a case study for both ship and platform related oil spills, Ocean Coast. Manag. 108 (2015) 140-146.

[31] F. Maes, National research council, oil in the sea III. Inputs, fates and effects, Int. J. Environ. Pollut 22 (2004) 743-744.

[32] Z.Y. Chen, J.C. Chen, Y. Zhao, Model test study on mooring line forces of 250,000 dwt tanker in tidal current, Ocean Eng. 16 (3) (1998) 45-53 (In Chinese).

[33] Y.P. Kang, Design for 52,000 dwt tanker base on common structure rules, Shanghai Jiao Tong University, Shanghai, 2008 (In Chinese).

[34] H. Liu, Introduction and application prospects of cosco shipyard $105000 \mathrm{t}$ shuttle tanker (In Chinese), Mech. Electr. Equip. 3 (2013) 35-37.

[35] J. Xu, Structural Design Applied with CCS Rules and Strength Assessment Based on CSR in Cargo Area of Oil Tankers about $150 \mathrm{~m}$ in Rule Length, Shanghai Jiao Tong University, Shanghai, 2009 (In Chinese).

[36] M. Verma, M. Gendreau, G. Laporte, Optimal location and capability of oil-spill response facilities for the south coast of Newfoundland, Omega 41 (5) (2013) 856-867.

[37] A.M. Caunhye, X. Nie, S. Pokharel, Optimization models in emergency logistics: a literature review, Socio-Econ. Plan. Sci. 46 (1) (2012) 4-13.

[38] C.C. Zhang, L. Han, X.J. Shi, Modified assessment methodology for mechanical recovery capacity for oil spill response at sea, Aquat. Procedia 3 (2015) 29-34.

[39] M. Fingas, Oil spills and respons. In: Springer Handbook of Ocean Engineering. Springer International Publishing, 2016, pp. 1067-1094.

[40] R. Asadpour, N.B. Sapari, Z.Z. Tuan, H. Jusoh, A. Riahi, O.K. Uka, Application of sorbent materials in oil spill management: a review, Casp. J. Appl. Sci. Res. 2 (2) (2013) 46-58. 